Licença CC BY: Artigo distribuído

sob os termos

Creative Commons, permite uso e

distribuição irrestrita em

qualquer meio

desde que o

autor credite

a fonte original.

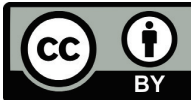

\section{OS VALORES PÚBLICOS E OS DESAFIOS DA RESPONSABILIZAÇÃO NAS PARCERIAS PARA O TURISMO EM ÁREAS PROTEGIDAS: UM ENSAIO TEÓRICO}

\author{
PUBLIC VALUES AND THE CHALLENGES OF ACCOUNTABILITY \\ IN PARTNERSHIPS FOR TOURISM IN PROTECTED AREAS: A \\ THEORETICAL CONTRIBUTION
}
VALORES PÚBLICOS Y DESAFÍOS DE RESPONSABILIDAD EN LAS ALIANZAS PARA EL TURISMO EN ÁREAS PROTEGIDAS: UNA CONTRIBUCIÓN TEÓRICA

CAMILA GONÇALVES DE OLIVEIRA RODRIGUES'

UNIVERSIDADE FEDERAL RURAL DO RIO DE JANEIRO, RIO DE JANEIRO, BRASIL

\author{
FERNANDO LUIZ ABRUCIO² \\ FUNDAÇÃO GETÚLIO VARGAS, SÃO PAULO, BRASIL
}

RESUMO: As instituições ambientais responsáveis pelas áreas protegidas no Brasil têm investido em parcerias com a iniciativa privada para apoiar a prestação de serviços de apoio ao turismo. O objetivo do artigo é apresentar um ensaio teórico-conceitual sobre valores públicos, com ênfase na responsabilização, que tendem a influenciar diretamente a forma como as parcerias são planejadas e implementadas na gestão do turismo em áreas protegidas. A literatura sobre valores públicos no âmbito das parcerias foi utilizada como chave de interpretação para o processo em curso na gestão da visitação em áreas protegidas, salientando assim um conceito utilizado com mais frequência pela literatura internacional, que faz a ponte entre os campos de Turismo e Administração Pública. Destaca-se que o debate sobre parcerias deve ir além da dicotomia público versus privado, incentivando a parceria norteada por valores públicos. Os valores públicos são de âmbito mais geral, vinculados a objetivos democráticos e republicanos, e de cunho específico, relacionados à política pública em pauta - no caso, a defesa do patrimônio público e a sustentabilidade no turismo. O artigo apresenta aspectos relevantes para a compreensão do impacto das parcerias para o desenvolvimento do turismo e para o alcance dos objetivos das áreas protegidas.

PALAVRAS-CHAVE: áreas protegidas; turismo; parcerias.

Professora Associada da Universidade Federal Rural do Rio de Janeiro. Doutora em Política e Gestão Ambiental pelo Centro de Desenvolvimento Sustentável da Universidade de Brasília. E-mail: camila.rodrigues. ufrrj@gmail.com. ORCID: 0000-0001-7076-790X.

2 Professor do Programa de Mestrado e Doutorado em Administração Pública e Governo FGV-EAESP. Doutor em Ciência Política pela Universidade de São Paulo. E-mail: fernando.abrucio@fgv.br. ORCID: 0000-00023883-9915. 


\begin{abstract}
Environmental institutions responsible for overseeing protected areas in Brazil have invested in partnerships with the private initiative to support tourism services. The current work aims to present a conceptual reflection on public values, with an emphasis on accountability, which tend to directly influence the way partnerships for the development of tourism in protected areas are planned and implemented. The literature on public values related to partnerships was used as a key to the interpretation for the management of public use in protected areas, thus highlighting a concept commonly used by international literature, which bridges Tourism and Public Management perceptions. The article highlight that the debate on concessions should go beyond the dichotomy of public versus private and should be guided by the perspective of a partnership based on public values. Public values are, in a more general scope, tied to democratic and republican objectives and, specifically, related to the public policy at hand - in this case, matters of defending Public Heritage and Sustainability in Tourism. The article highlights some aspects for understanding the impact of partnerships for the development of tourism and meeting the objectives of protected areas.
\end{abstract}

KEY WORDS: protected areas; tourism; partnerships.

RESUMEN: Las instituciones ambientales responsables de las áreas protegidas en Brasil han estado incentivando alianzas con el sector privado para apoyar la prestación de servicios de turismo. El objetivo de este trabajo es presentar un ensayo teórico y conceptual sobre valores públicos, con énfasis en la accountability, que tiende a influir directamente en la forma en que se planifican e implementan las asociaciones en la gestión del turismo en áreas protegidas. La literatura sobre valores públicos en el marco de las asociaciones se utilizó como clave para la interpretación del proceso continuo de gestión de visitas en áreas protegidas, destacando así un concepto utilizado con mayor frecuencia por la literatura internacional, que une los campos del Turismo y Administración Publica. Es de destacar que el debate sobre las asociaciones debe ir más allá de la dicotomía público versus privado, alentando la asociación guiada por los valores públicos. Los valores públicos son de alcance más general, vinculados a objetivos democráticos y republicanos, y de naturaleza específica, relacionados con la política pública en cuestión, en este caso, la defensa del patrimonio público y la sostenibilidad en el turismo. El artículo presenta aspectos relevantes para comprender el impacto de las asociaciones para el desarrollo turístico y el logro de los objetivos de áreas protegidas.

PALABRAS CLAVE: áreas protegidas; turismo Asociaciones

\title{
INTRODUÇÃO
}

As parcerias entre as esferas pública e privada no âmbito da gestão pública e na prestação de serviços para a sociedade ocorrem há várias décadas e por meio de diversos arranjos institucionais (Forrer et al., 2010). Contudo, desde a década de 1990, influenciadas pelos princípios da corrente neoliberal de desenvolvimento e pelas diretrizes da Nova Gestão Pública (New Public Management), as parcerias são incentivadas em vários países e em diversos setores do governo como uma alternativa para conduzir os desafios na esfera da gestão pública (Peters \& Pierre, 2010; Reynaers, 2013). 
Acompanhando esta tendência, os órgãos ambientais responsáveis pela gestão das áreas protegidas, como os parques, por exemplo, estão investindo em estudos e projetos relacionados à implementação de parcerias com a iniciativa privada para apoiar a gestão de áreas protegidas. No contexto desse artigo, as parcerias referem-se aos diferentes arranjos institucionais utilizados entre as esferas pública e privada, com e sem fins lucrativos, para a viabilização de serviços e atividades de apoio à recreação e ao turismo em áreas protegidas.

A concessão, a permissão e a autorização para uso privativo de bem público ou prestação de serviços de apoio visitação e ao turismo são comumente utilizadas para viabilizar a participação privada, com fins lucrativos. Além da utilização, de forma subsidiária ${ }^{3}$, de legislação para a prestação de serviços públicos, a Lei 13.688, de 28 de maio de 2018, autoriza o Instituto Chico Mendes de Conservação da Biodiversidade (ICMBio), responsável pela gestão de unidades de conservação federais, a conceder serviços ${ }^{4}$, áreas ou instalações para a exploração de atividades de visitação voltadas ao turismo, interpretação ambiental e recreação em contato com a natureza.

A referida Lei dispensa o chamamento público para celebração de parcerias, nos termos da Lei 13.019, de 31 de julho de 2014, que institui o Marco Regulatório das Organizações da Sociedade Civil (MROSC), com associações representativas das populações tradicionais para a exploração de atividades relacionadas ao uso público.

Diante deste cenário, este artigo tem como objetivo apresentar um ensaio teórico-conceitual sobre valores públicos, com ênfase na responsabilização, os quais tendem a influenciar diretamente o modelo e a forma como as parcerias são planejadas e implementadas no âmbito da gestão de áreas protegidas. Esta reflexão visa apontar alguns caminhos de interpretação sobre o contexto atual no qual são desenvolvidas as parcerias entre as esferas pública e privada para a promoção da recreação e do turismo em áreas protegidas. Tal debate, ademais, é relevante porque, por meio dele, se tem feito na literatura internacional a ponte entre os campos de Turismo e Administração Pública em torno de questões como a responsabilização, a regulação e o monitoramento no âmbito das parcerias (Manning \& More, 2002; Eagles, 2009; Randle \& Hoye, 2016; Dinica, 2018).

No Brasil, embora alguns estudos tenham abordado o desenvolvimento de parcerias, principalmente de concessões, para o turismo em parques (Rocktaeschel, 2006; Rodrigues \& Godoy, 2013; Braga, 2013; Matheus \& Raimundo, 2017), a discussão sobre os valores públicos que orientam essas iniciativas requer um maior aprofundamento, sobretudo quando se trata do impacto das parcerias para o alcance dos objetivos das áreas protegidas.

3 Ainda que alguns serviços de apoio à recreação e ao turismo, como hospedagem, alimentação, transporte, não sejam considerados no bojo da definição estrita de serviço público, a legislação e os princípios para a prestação de serviços públicos, por meio de concessão, permissão, autorização, entre outros instrumentos, são utilizados subsidiariamente pelos órgãos ambientais no âmbito da delegação de uso privativo de bem público (Rodrigues \& Godoy, 2013; Braga, 2013).

4 Tais concessões deverão observar o procedimento licitatório indicado na Lei 8.987, de 13 de fevereiro de 1995, também conhecida como a Lei das Concessões. 
O ponto central de reflexão deste artigo sugere que a responsabilização é tão ou mais importante que a forma de gestão pública ou privada. Neste sentido, uma parte desse debate passa pelo reconhecimento da complexidade inerente à relação entre as esferas pública e privada. Não se trata de olhar o público apenas como o "estatal" e condutor do "aparelho burocrático", e o privado como a instância que assume a gestão por ser mais eficiente e ter maior flexibilidade. Quando se trata da gestão de áreas protegidas, bens públicos de uso especial, é necessário problematizar essa dicotomia público-privada.

As noções de público e privado foram institucionalizadas ao longo do tempo por meios de modelos institucionais, mas também de valores que orientam cada um e, sobretudo, a relação entre eles. Assim, em vez de categorias separadas e dicotômicas, a abordagem contemporânea desses termos tende a ser relacional e contextualizada a partir de elementos históricos, sociais e políticos, considerando a complexidade dessa relação "pública e privada", suas imbricações, interfaces e contradições.

A utilização dos parques e demais áreas protegidas pode prever a implementação de infraestrutura e serviços prestados por meio de parcerias com instituições privadas, com ou sem fins lucrativos, conforme orientações de planejamento de cada área. Neste sentido, este artigo apresenta uma contribuição para o debate sobre os valores públicos que pode orientar as parcerias para a prestação de serviços de apoio à recreação e ao turismo nestas áreas.

\section{FUNDAMENTAÇÃO TEÓRICA: VALORES PÚBLICOS NAS PARCERIAS ENTRE AS ESFERAS PÚBLICA E PRIVADA}

Como precisar e expressar os valores públicos no âmbito das parcerias na gestão pública? Quais são os instrumentos que promovem e consolidam os valores públicos? De que forma a discussão sobre os valores públicos se relaciona com o tema da conservação do patrimônio ambiental e cultural utilizado para fins de recreação e turismo? Essas questões podem gerar pistas relevantes para uma melhor compreensão sobre a repercussão das parcerias na dinâmica de acesso e utilização de bens e serviços por parte da sociedade.

Para refletir sobre essas questões, trabalhos como os de Peters \& Pierre (2010), Reynaers (2013), Reynaers \& Grimmelikhuijsen (2015), Boyer, Van Slyke \& Rogers (2016), que discutem os valores públicos no âmbito das parcerias pública e privada para a prestação de serviços públicos, aportam elementos interessantes para se pensar o caso brasileiro.

Para Peters \& Pierre (2010), as parcerias sofrem com uma série de problemas, como direcionamento político, controle, transparência e accountability. Os autores salientam que a relação dos setores público e privado está se tornando cada vez mais assimétrica. O setor público é cada vez mais dependente do financiamento da iniciativa privada, mas o setor privado 
tem cada vez menos incentivos para se engajar com o setor público. Também salientam que o processo de implementação das parcerias tem gerado um compromisso significativo para o setor privado no sentido de desempenhar papéis "quase públicos", não apenas em termos de prestação de serviços, mas também em termos de assumir o "ethos público" e as noções de legalidade que são demandadas a partir da transferência de responsabilidade (p.47).

Os autores destacam que a lógica fundamental é que a componente pública da parceria representa e salvaguarda os valores públicos e o interesse público. Mas para que esse arranjo funcione, salientam que é essencial que os representantes do setor público conheçam e valorizem esses valores. Assim, sugerem que, para evitar as "armadilhas" de uma transparência inadequada no setor público, é necessário criar e manter mecanismos de accountability sobre estas estruturas.

A partir de pesquisas sobre a caracterização e a importância dos valores públicos nas parcerias público-privadas5, Reynaers (2013) aponta alguns elementos interessantes para se pensar no contexto das parcerias para a gestão de espaços públicos, como as áreas protegidas. De acordo com a autora, a literatura sobre os valores públicos preocupa-se com a questão de saber se o envolvimento do setor privado permite a salvaguarda e a consolidação de valores públicos, responsabilização (accountability), transparência, capacidade de resposta e qualidade.

De maneira geral, a responsabilização pode ser definida como um mecanismo através do qual as pessoas podem responsabilizar e cobrar os seus representantes para fazer valer os compromissos e as funções assumidas. Assim, "apesar do aumento do envolvimento do setor privado, o setor público ainda deve ser responsabilizado pela entrega do serviço público, mesmo quando já não fornece esses serviços em si" (Reynaers, 2013, p. 43). A autora também questiona - grau de responsabilização da administração pública na medida em que as decisões e as responsabilidades pela prestação de serviços são transferidas para o setor privado, distanciando assim o poder público do controle direto de determinadas atividades.

A transparência foi analisada por Reynaers \& Grimmelikhuijsen (2015) em outro trabalho no qual destacam a disponibilidade e o acesso à informação sobre custos, acordos e desempenho de serviços públicos. Nesse sentido, argumentam que um componente crucial na definição de transparência é a disponibilidade de informações sobre as parcerias, que não significa simplesmente ser visível ou acessível, mas também que pode ser entendida corretamente.

No que diz respeito à capacidade de resposta, trata-se de uma dinâmica de retorno por parte da gestão pública para a sociedade, no sentido de influenciar e ajustar a prestação de serviços públicos. Reynaers \& Grimmelikhuijsen (2015) salientam que a transferência de responsabilidade para o setor privado e a contratação de longo prazo tendem a diminuir a capacidade do governo

5 Estudos realizados no setor de transporte e infraestrutura. 
para influenciar os serviços para os quais ainda é responsável. Já a qualidade como um valor público refere-se ao grau de satisfação por parte do cidadão em relação aos serviços e aos produtos fornecidos por empresas privadas. Este valor expressa o constante equilíbrio entre a busca pela otimização financeira por parte do ente privado e a manutenção da qualidade do serviço prestado (Reynaers, 2013).

Mas Reynaers (2013) salienta que existem diversas interpretações na literatura da administração pública sobre a definição exata de valores públicos. Uma primeira fonte de ambiguidade decorre do adjetivo "público". Partindo-se de estereótipos, pode-se dizer que o setor público estaria associado a valores como a solidariedade e a responsabilidade, enquanto valores como a eficiência e a concorrência estariam vinculados ao setor privado. Contudo, muitos estudiosos contestam esta dicotomia, demonstrando que a fronteira entre os setores e seus valores correspondentes é tênue.

Como segundo ponto da ambiguidade, a autora cita a utilização do conceito de valores públicos para se referir a valores empíricos e normativos. Assim, "quando o conceito é usado de forma normativa, sugere questões sobre o que os valores públicos devem se parecer e quem deve decidir quais valores merecem o rótulo" (p. 43). E, por fim, argumenta que, embora os valores públicos possam ser importantes para organizações públicas e funcionários públicos, há evidências de que as empresas privadas também adotam e salvaguardam certos valores caracterizados como públicos.

Os valores públicos são expressos por meio de ações, decisões e atitudes por parte da esfera pública na sua relação com a sociedade. Neste sentido, os "valores" que permeiam o planejamento e a execução das parcerias podem incorporar questões específicas de uma agenda temática (turismo, ambiente, educação, cultura, pobreza). Desta forma, além dos valores públicos discutidos anteriormente, este artigo apresenta alguns elementos associados aos espaços públicos, como as áreas protegidas, que podem ser revelados e discutidos no âmbito das parcerias entre as esferas pública e privada. Um exemplo é a função pública associada à conservação do patrimônio natural e à utilização de bem de uso especial que está presente no processo de criação de um parque, por exemplo.

Dentre os usos possíveis e regulados nas unidades de conservação, a recreação e o turismo se destacam como atividades que visam promover um maior conhecimento sobre a função dessas áreas, sobretudo no que diz respeito aos serviços ecossistêmicos abrangidos, como proteção da biodiversidade, regulação climática, reprodução social e cultural, preservação de mananciais de água, dentre outros. 


\section{METODOLOGIA}

Para conduzir o debate proposto no artigo, a literatura que trata dos valores públicos no âmbito das parcerias para a prestação de serviços públicos, com ênfase na responsabilização, foi utilizada como chave de interpretação para o processo em curso na gestão da visitação em áreas protegidas.

Destacam-se na literatura internacional os trabalhos de Peters \& Pierre (2010), Reynaers (2013), Boyer, Van Slyke \& Rogers (2016) que, embora tratem de parcerias em outros setores, como o de transporte, por exemplo, abordam questões relevantes que podem subsidiar a reflexão no caso da gestão de áreas protegidas.

O trabalho desenvolvido pelo conselho científico do Centro Latinoamericano de Administración para el Desarrollo (CLAD, 2006) inspirou a análise sobre os diferentes tipos de responsabilização na administração pública, considerando a aproximação com o tema principal desse artigo.

No que diz respeito ao debate sobre a responsabilização no âmbito das concessões e demais parcerias para o desenvolvimento do turismo em áreas protegidas, as referências no Brasil ainda são incipientes (Braga, 2013; Rodrigues \& Godoy, 2013), mas na literatura internacional se destacam, no contexto deste artigo, os estudos desenvolvidos por Randle \& Hoye (2015) e Dinica (2018), que tratam dos mecanismos de regulação das atividades comerciais associadas ao turismo em áreas protegidas.

Além do levantamento e da análise de referencial bibliográfico, também foram consultados documentos institucionais (ICMBio, 2018) com informações sobre as parcerias nas áreas protegidas, principalmente nos parques nacionais brasileiros.

\section{RESPONSABILIZAÇÃO NA ADMINISTRAÇÃO PÚBLICA: QUAL A REPERCUSSÃO NAS PARCERIAS E NAS CONCESSÕES PARA A PRESTAÇÃO DE SERVIÇOS DE APOIO À RECREAÇÃO E AO TURISMO?}

O debate contemporâneo sobre a gestão pública envolve uma releitura sobre o papel do Estado e da sua relação com a sociedade. E, neste processo, a responsabilização (accountability) tornou-se uma palavra de ordem política adotada por diferentes setores do governo no contexto de novas formas de governança, dentre as quais se destacam as parcerias entre as esferas pública e privada na prestação de serviços (Steets \& Blattner, 2010).

A responsabilização se destaca em dois campos principais, o campo do desempenho da gestão pública, porque em grande medida a forma do Estado ser "accountable" aos cidadãos está relacionada à qualidade dos serviços públicos; e o campo da democratização, que é a forma pela qual os cidadãos participam das decisões. Essas duas dimensões são essenciais para o serviço 
público hoje, que precisa responder, concomitantemente, tanto às demandas de desempenho quanto às demandas de democratização.

Em sentido amplo, conforme destacado pelo conselho científico do Centro Latinoamericano de Administración para el Desarrollo (CLAD, 2006), os mecanismos de responsabilização funcionam como um "valor" que deve guiar os governos democráticos no sentido da prestação de contas à sociedade. Destaca-se também a responsabilização como um conceito multidimensional, uma vez que a sua efetivação pode ocorrer por meio de diferentes vertentes e instrumentos. O CLAD destaca cinco mecanismos de responsabilização: a) responsabilização pelos controles clássicos (procedimentais, como o controle judicial e o de contas); b) responsabilização pelo controle parlamentar; c) responsabilização pela introdução da lógica dos resultados; d) responsabilização pela competição administrada, e) responsabilização pelo controle social.

A responsabilização pela competição administrada, pela introdução da lógica dos resultados e pelo controle social apresenta elementos que podem ser abordados nas parcerias para a gestão de áreas protegidas. A responsabilização pela competição administrada e pela introdução da lógica dos resultados está relacionada ao campo do desempenho da gestão pública, enquanto que a responsabilização pelo controle social reforça o campo da democratização no processo de definição, implementação e monitoramento das parcerias.

A competição administrada baseia-se na composição e na concorrência entre diferentes setores - estatais, públicos não estatais e privados -, ampliando o leque de prestação de serviços, ao mesmo tempo em que impulsiona a oferta de melhores serviços e a prestação de contas às instituições envolvidas e aos cidadãos-usuários das políticas públicas. A responsabilização pela competição administrada significa que a concorrência é orientada por metas contratualizadas entre o órgão governamental ou uma agência reguladora e os prestadores de serviços. Neste processo, o Estado atua em um sistema de "quase-mercado" para evitar as consequências indesejáveis da concorrência, como o aumento da desigualdade na provisão (CLAD, 2006).

Um aspecto importante na responsabilização pela competição administrada é a ênfase no consumidor de serviços públicos. A participação do cidadão como consumidor ampliou o raio de responsabilização na administração pública, criando mais um modo de instaurar o processo de accountability. Neste contexto, é importante salientar que as categorias usuário, cliente, cidadão e consumidor indicam diferentes abordagens na prestação e no acesso aos serviços públicos (Derani, 2002; Rodrigues, 2018).

A introdução da lógica dos resultados no âmbito das parcerias para a prestação de serviços reforça as mudanças na relação entre a burocracia e a população. Essa lógica funcionaria como uma forma de aumentar a efetividade das políticas públicas na medida em que incorpora o feedback da população que utiliza os serviços, aproximando as demandas da sociedade à realização das políticas públicas. Neste sentido, a lógica dos resultados funciona numa dialética 
entre cidadão e Estado, incentivando a transparência por meio da geração de informação necessária ao acompanhamento de metas e resultados, que em última instância expressa o alcance de uma determinada política pública.

A responsabilização também diz respeito à ampliação da capacidade normativa e regulatória dos governos na medida em que o repasse de funções às organizações públicas não estatais e às organizações privadas não retira do Estado a responsabilidade de controlar as políticas. Isso porque "a especificidade da organização governamental deriva, em primeiro lugar, da motivação que a guia: enquanto as empresas buscam o lucro, os gestores públicos devem atuar conforme o interesse público" (CLAD, 2006, p. 26)

Na mesma linha, Forrer et al. (2010) salientam que as parcerias alteram a dinâmica de responsabilidade pública ao envolver parceiros privados na tomada de decisão governamental e na entrega de programas. Os termos e as condições deste envolvimento merecem atenção por parte dos funcionários públicos, a fim de garantir que os serviços públicos não sejam comprometidos em benefício dos lucros privados (Forrer et al., 2010).

A responsabilização nas parcerias também depende da definição clara dos papéis e das responsabilidades por parte dos envolvidos, fatores que influenciam diretamente a compreensão sobre a identidade institucional dos órgãos públicos por parte da sociedade. Assim, além dos instrumentos de accountability por desempenho, o controle social tem um lugar chave no processo de responsabilização das políticas públicas, pois busca garantir o sentido público de várias formas de atuação estatal, incluindo a concessão e as parcerias com o setor privado.

O envolvimento público requer um diálogo amplo a partir de uma série de eventos, reuniões, audiências e também mecanismos acessíveis de geração de conhecimento sobre as propostas. Nesse processo, surgem tensões e conflitos de interesse entre os diversos setores afetados direta e indiretamente pela a implementação da parceria. Portanto, a participação nos espaços de comunicação entre a sociedade e o Estado funciona como um aprendizado para ambas as partes, que pode inclusive gerar a revisão de uma proposta ou mesmo a sua paralização.

Baseando-se em uma literatura ampla sobre práticas de governança e em pesquisa realizada sobre as parcerias no setor de transporte, Boyer, Van Slyke \& Rogers (2016) destacam que o envolvimento público pode variar de formas unidirecionais de compartilhamento de informações, como distribuição de matérias de marketing ou propagandas, para canais de comunicação bidirecionais que não apenas informam os cidadãos, mas que incorporam suas opiniões nas decisões tomadas.

Mas o sucesso da participação não pode ser medido somente pela conquista de aliados para a proposta de articulação com o setor privado. Os mecanismos participativos constituem, antes de tudo, um valor democrático que está na base da responsabilização da gestão pública. Afinal, um dos pressupostos 
da responsabilização é o estabelecimento de um nível suficiente de transparência e acesso à informação por parte da sociedade (Bexell \& Mörth, 2010).

Assim, o debate sobre a responsabilização suscita também a abordagem de temas como a transparência e o envolvimento da sociedade, que estão presentes na literatura sobre os valores públicos no contexto das parcerias públicoprivadas (Peters \& Pierre, 2010; Reynaers, 2013; Reynaers \& Grimmelikhuijsen, 2015). E essa discussão pode gerar questões interessantes para se pensar as parcerias e as concessões em áreas protegidas e seus impactos nas políticas de turismo e conservação da natureza.

\section{O USO PÚBLICO DAS ÁREAS PROTEGIDAS E A PROTEÇÃO DO PATRIMÔNIO DE INTERESSE PÚBLICO}

O histórico de proteção de áreas naturais para fins diversos como a manutenção do equilíbrio hidrológico, da qualidade do clima, da diversidade de espécies, da reprodução social, da paisagem, de espaços para lazer, foi registrado por diversos autores, que também analisaram os interesses e os conflitos associados à criação dessas áreas (Pádua, 1987; Diegues, 1996; Drummond, 1997).

A criação dos primeiros parques nacionais brasileiros na década de 1930 fazia parte de um projeto mais amplo de nação, comandado pelo Estado. No Brasil, a Constituição Federal de 1988 tratou dos espaços territoriais especialmente protegidos, atribuindo ao poder público o dever de criação destas áreas com o objetivo de conservação da biodiversidade (Leuzinger, 2007; Fernandez, 2011).

Todavia o processo de criação e utilização dessas áreas é acompanhado por situações conflituosas entre povos que ocupam (ou ocupavam) tradicionalmente estas áreas e os órgãos ambientais (Barreto Filho, 2006; Spinola, 2013; Fernandez, 2016). Embora não seja foco do artigo discutir os conflitos relacionados ao estabelecimento de áreas protegidas, é importante salientar que esse processo expressa visões distintas sobre o significado e a função dessas áreas e, consequentemente, sobre o planejamento para a utilização dos recursos. Por se tratar de uma categoria de proteção integral, que não permite a permanência de populações humanas nos seus limites, os parques (nacional, estadual, municipal) possibilitam apenas o uso indireto da natureza, por meio de atividades como a visitação, por exemplo. Neste sentido, a partir do momento em que uma determinada área é destinada à criação de um parque, seus usos se modificam de atividades tradicionais para atividades "modernas", como o turismo em contato com a natureza.

Os parques são considerados bens públicos de uso especial, conforme definições do Código Civil, que classificam os bens públicos em diferentes categorias. Os bens públicos de uso especial se destinam a viabilizar serviço ou utilidade pública. Assim, ainda que possam ser usufruídos pela coletividade, sua utilização é objeto de restrição e condicionamento (Braga, 2013). 
Nesse contexto, ainda que os parques contemplem a destinação específica de visitação, de acordo com a Lei 9.985, de 18 de julho de 2000, que estabelece o Sistema Nacional de Unidades de Conservação da Natureza (conhecida como a Lei do SNUC), sua finalidade se insere no objetivo precípuo de proteção e utilização sustentável da biodiversidade (Brasil, 2000; Braga, 2013).

Em um artigo sobre os significados do termo "público" no contexto do acesso aos serviços de apoio ao turismo nos parques nacionais, Rodrigues \& Irving (2015) salientam a natureza das atividades públicas no sentido de proteção de um bem "coletivo", e não apenas no sentido de pertencer ao Estado, envolvendo uma maior complexidade na abordagem dos valores públicos associados à proteção do patrimônio e do interesse público.

Em 2006, foi criado o Instituto Chico Mendes de Conservação da Biodiversidade (ICMBio), responsável pela execução de ações da política nacional de unidades de conservação no tocante às áreas federais instituídas pela União. A missão da instituição é proteger o patrimônio natural e promover o desenvolvimento socioambiental. O ICMBio é responsável pela gestão de 334 unidades de conservação federais, o que corresponde a 9\% do território continental protegido. Dentre as unidades de conservação existentes, 74 são parques nacionais, categoria de manejo que evidencia a recreação e o turismo em contato com a natureza como um de seus objetivos de criação (ICMBIO, 2018).

Até agosto de 2019, sete parques nacionais no Brasil apresentavam contratos de concessão para serviços de apoio ao turismo vigentes ou em fase inicial de operação: Parque Nacional da Tijuca (RJ), Parque Nacional de Iguaçu (PR), Parque Nacional Marinho de Fernando de Noronha (PE), Parque Nacional da Serra dos Órgãos (RJ), Parque Nacional da Chapada dos Veadeiros (GO), Parque Nacional do Itatiaia (RJ/MG) e Parque Nacional do Pau Brasil (BA). E está previsto o lançamento de editais de concessão em mais 5 parques nacionais até 2020 (ICMBio, 2018). Tais iniciativas estão sendo fomentadas também no âmbito do Programa Nacional de Desestatização (PND), que incluiu os Parques Nacionais de Lençóis Maranhenses (MA), Jericoacoara (CE) e Iguaçu (PR) (BRASIL, 2019).

Outra iniciativa em curso, denominada "Parcerias Ambientais Público Privadas (PAPP)", tendo como instituição gestora o Instituto Brasileiro de Administração Municipal (IBAM), em parceria com o Instituto Chico Mendes de Conservação da Biodiversidade, e com a cooperação do Banco Interamericano de Desenvolvimento (BID) e da Caixa Econômica Federal, tem motivado o estudo e a consolidação de diferentes arranjos de parceria para apoiar a gestão de áreas protegidas (PAPP, 2018)․

Observa-se, tanto no âmbito federal, como também nas recentes iniciativas do governo dos estados de São Paulo, Minas Gerais e Rio de Janeiro, uma tendência em acelerar os processos de concessão para a iniciativa privada para a gestão e a prestação de serviços de apoio à recreação e ao turismo em 
parques. Contudo, tais iniciativas, se não forem adequadamente planejadas e estiverem sintonizadas com o contexto local, podem gerar uma série de impactos ambientais e socioeconômicos indesejáveis. Questões como a diversidade de oportunidades de visitação e os objetivos de criação das áreas protegidas relacionados à proteção da biodiversidade e à sustentabilidade devem ser respeitados no processo (Eagles 2009; Wyman et al., 2011; Rodrigues \& Godoy 2013; Braga; 2013, Matheus \& Raimundo, 2017).

Tem-se fortalecido o argumento de que as dificuldades fiscais dos Estados e o aumento das demandas relacionadas à implementação e à gestão de áreas protegidas reduzem a capacidade das instituições ambientais de resolverem sozinhas o problema. Diante disso, uma das soluções - não a única passa pela ampliação da participação privada na gestão destas áreas (Wyman et al., 2011; Rodrigues \& Godoy, 2013).

Assim, em um cenário no qual o modelo de desenvolvimento evidencia os cortes públicos em áreas como cultura, educação e ambiente, a iniciativa privada entra em cena com o argumento de maior capacidade de investimento, portando valores como flexibilidade, inovação e foco nos resultados. O posicionamento contrário a essa tendência "moderna" da gestão pública é encarado muitas vezes como uma mera postura ideológica e crítica ao modelo neoliberal de apropriação dos espaços públicos. Contudo, o financiamento privado para a prestação de serviços para a sociedade reflete também uma postura ideológica que encontra no mercado as principais soluções para a gestão.

A perspectiva da parceria orientada por valores públicos questiona a dicotomia na forma de gestão dos parques. Dessa visão dicotômica surgem interpretações equivocadas, como a utilização do termo privatização associado ao processo de concessão para a prestação de serviços de apoio ao turismo em áreas protegidas. O termo indicado para esse modelo de parceria, conforme destaca Braga (2013), é a concessão de uso privativo de bem público.

Entretanto, dependendo da forma como a concessão é planejada e implementada, a promoção da iniciativa pode sugerir, principalmente quando divulgada em jornais de grande circulação, uma "privatização", ainda que a expressão não se aplique em termos legais, pois a área continua sendo pública. Mas, uma vez que as possibilidades de uso e recreação em uma determinada área estão prioritariamente vinculadas a uma concessão e ao pagamento de um determinado valor, além da cobrança de ingresso para acessar a área, tal situação pode sugerir uma interpretação equivocada por parte da sociedade. Nesse processo, a capacidade dos órgãos públicos de gerir os contratos e a de promover a identidade e os objetivos das áreas protegidas são questões que precisam ser consideradas quando a lógica da iniciativa privada impõe uma linguagem diferente e novas funções para os gestores dessas áreas.

O debate sobre a função pública de áreas protegidas vem ocorrendo em outros países, como nos Estados Unidos (Maning \& More, 2002), por 
exemplo, que desenvolveram um modelo de parque no qual não é permitida a residência de populações, porém incentiva o uso público como uma das principais estratégias para fortalecer o "parque nacional" como identidade e símbolo nacional.

No início dos anos 2000, Manning \& More (2002) chamaram a atenção para a função pública dos parques nacionais e demais áreas protegidas no contexto das políticas públicas nos Estados Unidos. Um dos questionamentos iniciais dos autores é: O que diferencia os parques públicos e os torna necessários? Quais valores que estão associados à proteção e à utilização dessas áreas? Os autores destacam que, numa sociedade que se orgulha de soluções baseadas no mercado para os diversos problemas de ordem social, é necessário deixar claro quais os valores e os interesses públicos são importantes e por quais razões (p. 24). Como exemplo, os autores citam o caso dos "playgrounds" públicos, que foram construídos a partir de uma demanda social, pois as mães buscavam lugares seguros, estimulantes e educativos para os seus filhos brincarem. Também citam o estabelecimento de áreas de camping públicas como incentivo para os cidadãos explorarem o país e conhecerem a sua história natural e cultural.

Neste contexto, Manning \& More (2002) exploram a recreação em contato com a natureza como um valor público fundamental que pode ser aproveitado para experiências de lazer orientadas para a família, bem como oportunidades para explorar a natureza e ampliar o conhecimento sobre o ambiente local. Também destacam os valores culturais, históricos e ecológicos associados à proteção do patrimônio natural. Esses diferentes valores representam "combinações de funções que nos ajudam a entender o papel único que os parques públicos podem desempenhar na sociedade contemporânea" (p. 28).

O processo de patrimonialização de bens naturais e culturais é permeado de interesses, estratégias e visões sobre como proteger tais bens. Isso denota a complexidade presente na gestão do patrimônio natural e cultural por meio dos parques públicos. A gestão deste patrimônio requer uma abordagem intergeracional como prerrogativa de qualquer iniciativa de utilização e apropriação destas áreas. Neste sentido, o debate sobre o acesso e a utilização do patrimônio público passa, necessariamente, por questões relacionadas aos direitos difusos e intergeracionais que impõem, sob a ótica da política pública, a observância do interesse público.

\section{REFLEXÕES SOBRE A RESPONSABILIZAÇÃO E A REGULAÇÃO NAS PARCERIAS PARA O DESENVOLVIMENTO DO TURISMO EM ÁREAS PROTEGIDAS}

Quando se trata de uma parceria entre as esferas pública e privada para a prestação de serviços de apoio à recreação e ao turismo em áreas protegias, e considerando a missão do ICMBio e dos órgãos ambientais estaduais no tocante à proteção do patrimônio natural e cultural, cabe à instituição o balanço constante 
entre o interesse público e o privado. Assim, conforme destaca Forrer et al. (2010), as parcerias entre as esferas pública e privada precisam ser administradas pelo governo como uma forma de garantir que os interesses públicos sejam atendidos ao longo do acordo e, para tanto, os gestores públicos devem estar preparados para a tarefa de regular e construir valores públicos, inclusive incorporando setores sociais amplos e os usuários desse serviço em suas decisões.

O Estado, porém, também sofre pressão e influência de diversos setores econômicos e, portanto, não está isento de situações e tomada de decisões que podem privilegiar determinados setores. Como aponta Bresser-Pereira (1998), um dos objetivos clássicos da administração pública é a proteção do patrimônio público contra a captura por interesses privados. E, numa abordagem sobre direitos, o autor defende a noção de "direitos republicanos" relacionado ao processo de democratização e aos interesses difusos como campo de discussão sobre o direito ao patrimônio ambiental e cultural. Assim, segundo essa visão, a cidadania só se completa na medida em que os cidadãos têm a consciência do interesse público e condições de defender o patrimônio público em geral cultural, ambiental e econômico.

No caso dos parques, trata-se de áreas que abrigam e protegem, a um só tempo, o patrimônio ambiental e cultural. Deste modo, a "natureza" da política pública e a "natureza" do serviço daquela política pública impactam o desenho dos valores públicos, como a responsabilização. Assim, o modelo de gestão das parcerias nos setores de turismo, transporte, educação, saúde, ambiente são diferentes e dialogam com a especificidade da política pública em questão. Isso significa dizer que em cada política pública a combinação entre as esferas pública e privada será diferente, pois essas categorias irão interagir em contextos diversos.

A responsabilização no processo de planejamento e implementação das parcerias e das concessões em parques sugere um debate relevante no que tange à ampliação da capacidade normativa e de monitoramento dos efeitos destes arranjos institucionais. De que forma os efeitos das parcerias são divulgados para a sociedade? Como o recurso obtido a partir dos contratos de concessão e ingressos são aplicados? Quais são os canais de comunicação entre visitantes, órgãos gestores dos parques e concessionárias? Quais são os critérios utilizados pelos órgãos gestores para definir as atividades e os serviços que serão objeto de parceria e concessão? Essas questões dizem respeito ao envolvimento público, ao controle social, à transparência, à capacidade de resposta no âmbito das parcerias e das concessões em parques.

Com o objetivo de subsidiar a construção de um arcabouço teórico para a regulação das concessões em áreas protegidas, sobretudo no que diz respeito à sustentabilidade no turismo, Dinica (2018) destaca a crescente demanda pelo turismo em áreas protegidas e os desafios que os países ainda enfrentam na regulação, no monitoramento e na gestão dos contratos de parceria e concessões. 
Em um estudo de caso sobre a regulação das atividades comerciais nos parques nacionais da província de Victoria, na Austrália, Randle \& Hoye (2015) destacam aspectos interessantes para se pensar nos mecanismos institucionais para monitorar e regular essas atividades. $\bigcirc$ "Parks Victoria" é responsável pela administração de 45 parques nacionais e atuam em parceria com os "operadores de turismo comercial", constituídos por indivíduos ou organizações que realizam atividades (por exemplo, visita guiada, evento especial ou instalação) que resultam em algum grau de retorno comercial (Randle \& Hoye, 2015).

A presença do setor privado nos parques nacionais australianos tem aumentado na medida em que o mercado turístico capitaliza o crescente nicho de turismo baseado na natureza e, ao mesmo tempo, o financiamento do governo diminui, limitando os recursos públicos para fornecer os serviços de apoio ao turismo. Dentre os mecanismos citados por Randle \& Hoye (2015) para regular as atividades comerciais nos parques do estado de Victoria, destacamse os seguintes:

- estratégias de comando e controle: são os regulamentos exigíveis por lei que definem as regras e as restrições à atividade comercial, como também as penalidades em caso do não cumprimento. Envolvem parâmetros quantificáveis como o número de visitantes permitidos em uma área, indicadores de impacto, respeito às normas de cada área. Incluem a emissão de licenças de turismo comercial e licenças de recreação concedidas pela administração para controlar o quê, como e quantas atividades serão realizadas dentro de um parque nacional. Envolvem também o conhecimento por parte dos operadores comerciais sobre os regulamentos e as regras de utilização e conservação da área.

- estratégias de incentivo: são aquelas que recompensam os operadores que alcançarem os resultados e o desempenho desejados. Também envolvem estratégias que penalizam os operadores por condutas indevidas e descumprimento de normas. Isso pode incluir, por exemplo, taxas reduzidas para os operadores que apresentam melhores práticas na gestão ambiental.

- controles de aproveitamento do mercado: são os regulamentos que visam assegurar a concorrência no mercado. O processo de manifestação de interesse, utilizado para embasar futuras concessões e operações comerciais, é uma forma de regulamentação que o governo adota visando estimular a concorrência entre os interessados. No contexto da concorrência destaca-se a atuação de empresas de diferentes tamanhos e capacidades de investimento. O governo do estado de Victoria argumentou que a infraestrutura turística geraria benefícios econômicos para a região. Contudo, as partes interessadas alegaram que uma superestrutura de turismo provavelmente demandaria o fornecimento de serviços por grandes empresas de Melbourne, em vez de empresas locais. Assim, as partes interessadas atribuíram grande importância às parcerias que possuam valores compatíveis com o Parque Nacional. O "tipo certo de investidor" compartilharia valores ambientais e trabalharia com a região, estimulando a economia (p.145). 
Os mecanismos de regulação das atividades comerciais citados Randle \& Hoye (2015) apresentam aspectos interessantes sobre a dinâmica de prestação de serviços e pode-se dizer que guardam uma relação com os instrumentos da responsabilização pela "competição-administrada" (CLAD, 2006), na medida em que constituem instrumentos de controle, de concorrência a partir de metas e indicadores de desempenho, e buscam aumentar a responsabilidade e a responsividade dos prestadores de serviços. Tais mecanismos engendram uma nova lógica na esfera da administração pública e, consequentemente, um campo de conhecimento no âmbito dos órgãos ambientais.

Destacam-se também, no caso dos parques nacionais brasileiros, as iniciativas do setor de turismo contextualizadas com as características socioeconômicas regionais, considerando empreendimentos de diferentes tamanhos e capacidades de investimento. Tal aspecto remete à discussão do empreendedor "situado", inspirado no conceito de "turismo situado" (Zaoual, 2009), pautado por questões éticas, geracionais, simbólicas (Bartholo, Sansolo, Bursztyn, 2009; Pimentel et al., 2013).

Assim, a responsabilização no âmbito das parcerias é caracterizada por um forte componente de geração e disseminação de informações para a sociedade a partir do monitoramento e da regulação das atividades comerciais. Neste sentido, com a ampliação dos contratos de parceria e o envolvimento crescente do setor privado na gestão do turismo em parques nacionais e outras áreas protegidas, faz-se necessário também o aumento da capacidade administrativa dos órgãos gestores para gerenciar e monitorar as atividades do setor.

\section{CONSIDERAÇÕES FINAIS}

Este artigo buscou desvelar algumas conexões entre o debate sobre os valores públicos nas parcerias público-privadas, em especial nas parcerias e nas concessões para a prestação de serviços de apoio à recreação e ao turismo em áreas protegidas.

Observa-se que o debate sobre as concessões e as parcerias no âmbito da política pública de conservação da natureza é orientado principalmente por questões de ordem econômico-financeira, influenciado também pelas medidas de ajuste fiscal que vêm promovendo cortes orçamentários em agendas setoriais, como a da gestão ambiental, por exemplo. Assim, as parcerias são pautadas em virtude da urgência do Estado em promover alternativas para enfrentar a escassez de recursos e pessoal. Contudo, ao criar uma determinada área de conservação, o governo assume também o compromisso de viabilizar condições adequadas para a implementação destas áreas.

Há quatro considerações que emergem da reflexão conceitual com impacto importante a partir da experiência brasileira. A primeira é que o debate sobre concessões deve ir além da dicotomia público versus privado, incentivando 
a parceria norteada por valores públicos. Sendo verdadeira essa premissa, é preciso inicialmente identificar quais são os valores públicos norteadores, para depois construir as condições para sua efetivação.

Os valores públicos são de âmbito mais geral, vinculados a objetivos democráticos e republicanos, e de cunho específico, relacionados à política pública em questão - no caso, as questões da defesa do Patrimônio Público e da Sustentabilidade no Turismo. Essa é a segunda conclusão do artigo. No caso dos parques e demais áreas protegidas, é necessário garantir valores gerais como transparência, participação e qualidade da gestão (em termos de monitoramento da contratualização e do planejamento geral da política). Mas os princípios particulares do setor também são estratégicos, de modo que a garantia de valores vinculados ao acesso ao patrimônio cultural e ambiental deve estar presente.

Em terceiro lugar, a efetivação da responsabilização nos processos de parceria e concessão constitui o principal desafio no caso dos parques e demais áreas protegidas. Do mesmo modo que a delegação para a iniciativa privada, com ou sem fins lucrativos, pode ser um passo importante na resolução dessa questão, esse arranjo somente poderá alcançar bons resultados se o Estado tiver a capacidade de construir, regular e repensar continuamente essa relação contratualizada entre o governo e o provedor.

Por fim, a discussão da responsabilização pública nas parcerias e nas concessões em áreas protegidas possibilita uma ponte importante entre os campos de Turismo, Lazer e Administração Pública, especialmente na temática relacionada à utilização do patrimônio ambiental e cultural para fins de recreação e turismo. Esse debate pode trazer novos ângulos para as pesquisas no campo do Turismo e áreas afins, e motivar estudos que ampliem o conhecimento sobre o impacto das parcerias entre as esferas pública e privada no turismo em áreas protegidas.

\section{AGRADECIMENTO}

À Fundação Getúlio Vargas/Escola de Administração de Empresas de São Paulo (FGV/EAESP).

\section{REFERÊNCIAS BIBLIOGRÁFICAS}

Barreto Filho, H. T. (2004). Notas para uma história social das áreas de proteção integral no Brasil. In: Ricardo, F. (org.). Terras Indígenas \& Unidades de Conservação da Natureza: o desafio o das sobreposições. São Paulo: Instituto Socioambiental. Disponível em: <http://www.iieb.org.br/arquivos/artigo_ henyo.pdf. Acesso em: jul. 2017.

Bartholo, R; Sansolo, D. G; Bursztyn, I. (Org.). (2009). Turismo de Base Comunitária: diversidade de olhares e experiências brasileiras. Rio de Janeiro: Letra e Imagem. 
Bexell, M. \& Mörth, U. (2010). Democracy and Public-Private Partnerships in Global Governance. Houndsmills, UK: Palgrave Macmillan.

Braga, A. S. (2013). Parques Nacionais: participação privada na viabilização do uso público. Curitiba: Edições CRV.

Brasil. (2000) Lei No 9.985, de 18 de julho de 2000 e Decreto 4.340, de 22 de agosto de 2002. 3ed. Brasília: Ministério do Meio Ambiente / Secretaria de Biodiversidade e Florestas, 52p.

Brasil. (2019). Resolução 79, de 21 de agosto de 2019. Presidência da República. Conselho do Programa de Parcerias de Investimentos da Presidência da República.

Bresser Pereira, L. C. (1998). Reforma do Estado para a cidadania: a reforma gerencial brasileira na perspectiva internacional. São Paulo: Ed. 34; Brasília: ENAP.

Boyer, E. J.; Van Slyke, D. M; Rogers, J. D. (2016). An Empirical Examination of Public Involvement in Public-Private Partnerships: Qualifying the Benefits of Public Involvement in PPPs. Journal of Public Administration Research and Theory. 45-61. DOI: 10.1093/jopart/muv008.

Buckley, R. (2012). Sustainable Tourism: Research and Reality. Annals of Tourism Research, $39(2)$, p. $528-546$.

CLAD. Conselho Latinoamericano de Administração Pública. (2006). In: Bresser-Pereira, L. C. Grau, C. N. Responsabilização na administração pública. São Paulo: CLAD/ Fundap.

Derani, C. (1997). Direito Ambiental Econômico. 3a ed. São Paulo: Max Limonad.

Diegues, A. C. S. (1996). O mito moderno da natureza intocada. São Paulo: Hucitec, 1996.

Dinica, V. (2018). The environmental sustainability of protected area tourism: towards a concession-related theory of regulation. Journal of Sustainable Tourism, 26:1, 146164, DOI: 10.1080/09669582.2017.1322599.

Drummond, J. A. (1997). Devastação e preservação ambiental no Rio de Janeiro - os parques nacionais do Estado do Rio de Janeiro. Niterói: EDUFF - Universidade Federal Fluminense, 1997.

Eagles, P. (2009). Governance of recreation and tourism partnerships in parks and protected areas. Journal of Sustainable Tourism. Vol. 17. N². 231-248.

Fernandez, A. C. F. (2011). Um Rio de florestas: uma reflexão sobre o sentido de criação dos parques na cidade do Rio de Janeiro. Estudos Históricos (Rio de Janeiro), v. 24, p. 141-161

(2016). O sertão virou parque: natureza, cultura e processos de patrimonialização. Estudos Historicos (Rio de Janeiro), v. 29, p. 127-146. 
Forrer, J.; Kee, J. E.; Newcomer, K. \& Boyer, E. (2010). Public-Private Partnerships and the Public Accountability Question. Public Administration Review. May-June. 2010. P. 475-485

ICMBIO. (2018). Parques do Brasil, visitar é proteger. Estratégias de implementação da visitação em unidades de conservação federais: prioridades de execução 20182020. Coordenação Geral de Uso Público e Negócios/Instituto Chico Mendes de Conservação da Biodiversidade. Brasília (DF). Disponível em: www.icmbio.gov.br. Acesso em nov.2018.

Leuzinger, M. (2009). Natureza e Cultura - Unidades de Conservação de Proteção Integral e Populações Tradicionais Residentes. Instituto Brasileiro de Advocacia Pública, Letra da Lei, Curitiba (PR).

Manning, R. \& More, T. (2002). Recreational Values of Public Parks. The George Wright Forum, 19 (2), 21-30.

Matheus, F. S. \& Raimundo, S. (2017). O resultado das políticas públicas de ecoturismo em unidades de conservação no Brasil e no Canadá. Revista Brasileira de Pesquisa em Turismo, 11 (3), p. 454-479. DOI: http://dx.doi.org/10.7784/rbtur.v1 1i3.1336

Pádua, J. A. (1987). Natureza e projeto nacional: as origens da ecologia política no Brasil. In: PÁDUA, J. A. (Org.). Ecologia e política no Brasil. Rio de Janeiro: Iuperj.

Peters, B.G. \& Pierre, J. (2010). Public-Private and the Democratic Deficit: Is PerformanceBased Legitimacy the Answer? In: Bexell, M. \& Mörth, U. Democracy and PublicPrivate Partnerships in Global Governance. Houndsmills, UK: Palgrave Macmillan. p. 41-54.

Pimentel, A.; Violento, A.; Rodrigues, C. G. O.; Juliao, D. P.; Juer, E.; Lohmann, J. B. (2013). Empreendedorismo e formalização de atividades de turismo em ambientes naturais. Revista Acadêmica Observatório de Inovação do Turismo, v. VII, p. 5-32.

Randle, R. \& Hoye, R. (2016). Stakeholder perception of regulating commercial tourism in Victorian National Parks, Australia. Tourism Management 54138 - 149. http://dx.doi. org/10.1016/j.tourman.2015.11.002

Reynaers, A. M. (2013). Public Values in Public-Private Partnerships. Public Administration Review, Vol. 74, 11, pp. 41-50. The American Society for Public Administration. DOI: 10.1111 puar. 12137.

Reynaers, A. M. \& Grimmelikhuijsen, S. (2015). Transparency in Public-private partnerships: not so bad after all. Public Administration Review. DOI: 10.1111/padm 12142.

Rocktaeschel, B. M. M. M. (2006). Terceirização em Áreas Protegidas - estímulo ao ecoturismo no Brasil. São Paulo: Editora SENAC.

Rodrigues, C. G. O.; Godoy, L. R. C. (2013). Atuação pública e privada na gestão de unidades de conservação: aspectos socioeconômicos da prestação de serviços de apoio à visitação em parques nacionais. Desenvolvimento e Meio Ambiente, v.28, 75-88. 
Rodrigues, C. G. O; Irving. M. Os significados de "público" e o compromisso de inclusão social no acesso aos serviços em apoio ao turismo em parques nacionais. In: IRVING, M; RODRIGUES, C. G. O; RABINOVICl, A.; COSTA, H. A. (orgs.) Turismo, Áreas Protegidas e Inclusão Social: diálogos entre saberes e fazeres. Rio de Janeiro: Folio Digital: Letra e Imagem. p.113-142.

Rodrigues, C. G. O. (2018). "Visitante-cidadão" e "Visitante-consumidor": reflexões o uso público dos parques nacionais. IN: NASCIMENTO, E.; COSTA, H.A (orgs.) Turismo e Sustentablidade: verso e reverso. Rio de Janeiro: Garamond. p. 51-64.

Spinola, C. A. (2013). Parques nacionais, conservação da natureza e inserção social: uma realidade possível em quatro exemplos de cogestão. Revista Turismo Visão e Ação Eletrônica, Vol. 15 - n¹, pag. 71-83.

Steets, J; Blattner, L. (2010). Partnership Accountability Need Not To Be Democratic Accountability. In: BEXELL, M. \& Mörth, U. Democracy and Public-Private Partnerships in Global Governance. Houndsmills, UK: Palgrave Macmillan. p. 57-78.

Wyman, M.; Barborak, J. R.; Inamdar, N.; Stein, T. (2011). Best Practices for Tourism Concessions in Protected Areas: A Review of the Field. Forests. 2, 913-928. DOI: 10.3390/f2040913.

Zaoual, H. (2008). Do turismo de massa ao turismo situado: quais as transições? Caderno Virtual de Turismo, v. 8, n. 2. p. 1-14.

\section{Contribuições de cada autor na elaboração do artigo:}

Camila Gonçalves de Oliveira Rodrigues: Concepção da pesquisa, revisão da literatura, discussão e análise dos resultados.

Fernando Luiz Abrucio: Fundamentação, revisão da literatura, discussão e análise dos resultados.

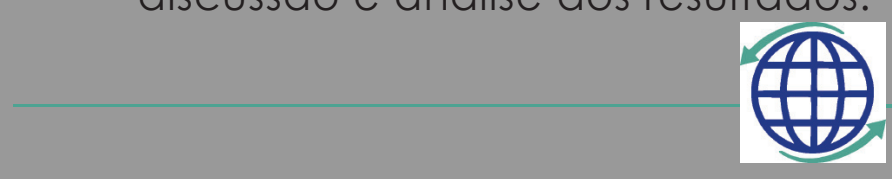

